\title{
Natural Egg Mortality of the African Grey Tree Frog, Chiromantis xerampelina (Amphibia: Rhacophoridae)
}

Allingham SM*

Prospect Street, Alfreton, Derbyshire, United Kingdom

${ }^{*}$ Corresponding author: Allingham SM, Prospect Street, Alfreton, Derbyshire, DE55 7GY, United Kingdom, Tel: + 447708881132, E-mail: natrix36@hotmail.com

Citation: Allingham SM (2017) Natural Egg Mortality of the African Grey Tree Frog, Chiromantis xerampelina (Amphibia: Rhacophoridae). J Vet Sci Ani Husb 5(1): 109. doi: 10.15744/2348-9790.5.109

Received Date: December 01, 2014 Accepted Date: February 25, 2017 Published Date: February 28, 2017

\begin{abstract}
Rainfall patterns are recognised as important for normal ecosystem functioning in arid environments. Most attempts made to understand the effect of rainfall on amphibian ecology have focused on long-term rather than short-term trends. Here, factors effecting embryonic mortality and clutch size of the African foam nesting frog Chiromantis xerampelina were examined at two ponds from April - June in 2011-2012 in Malawi. A total of 73 foam nests were monitored following spawning. On average $29 \%$ of eggs in 2011 and $26 \%$ in 2012 suffered mortality from both ponds and this mortality significantly varied between nests. Linear regression showed that the date of spawning had a significant effect on mortality due to moisture requirements of the eggs. The height of nests over the water surface had a negative impact on clutch size and increased rainfall decreased egg mortality in both years at both ponds. In a changing climate, with rainfall projected to become more infrequent in this region, organisms may not be able to rely on rainfall patterns as cues for reproduction, which may have a negative impact on amphibian populations.
\end{abstract}

Keywords: Chiromantis; Foam nests; Embryonic mortality; Climate patterns

\section{Introduction}

Knowledge on egg and larval survival is essential to understand the population dynamics of amphibians; however, due to the difficulties associated with assessing the survival rate of amphibian embryos and larvae under natural conditions, detailed knowledge of natural survivorship is limited to a few species and populations [1]. Rainfall, oxygen, ultraviolet radiation and temperature can also interact with biotic factors and influence mortality and hatching rate [2-4]. Embryos from amphibian egg clutches are surrounded by a protective perivitelline membrane containing perivitelline fluid and a jelly envelope composed of a variable number of layers [5]. Ambient moisture can influence the physical properties and structure of the embryos and the surrounding protective layers and can potentially alter the ability of embryos to hatch. This is particularly important for the many tropical species known to lay their eggs out of the water, thereby exposing their eggs to variable environmental conditions. Annual and seasonal levels of rainfall are projected to change throughout the twenty-first century [6,7] and as a result, mortality of terrestrial amphibian eggs is predicted to increase in the tropics [8,9]. Most studies considering the effect of rainfall on seasonal growth and survival have focused on seasonal or annual weather patterns [10-12]; but whereas such large-scale rainfall trends can be useful in explaining community level dynamics [13], they may not reveal the specific mechanisms driving individual mortality. In order to elucidate the effect of short term environmental fluctuations on growth and development, rainfall patterns should be considered on a much shorter timescale $[2,14]$.

The African grey tree frog, Chiromantis xerampelina, is a large species of the family Rhacophoridae. Males usually reach 43-75mm and females are around $60-90 \mathrm{~mm}$ (snout to vent length). This species is mainly distributed from coastal Kenya to the northeastern South Africa and inland to the North East of Namibia. It occupies a variety of habitats including savannah, shrubland, forests, pastureland and urban areas [15].

The prominent breeding and mating system (polyandry and formation of foam nests) of C. xerampelina appeal to ecologists and has been the focus of attention in many ecological and zoological studies [16-19]. Female C. xerampelina construct foam nests attached to tree branches along the shores of still water bodies where the tadpoles fall and complete their development [15]. The foam of the nest prevents direct observation of the eggs and embryos; therefore, little information is available regarding the embryonic morality and clutch size of C. xerampelina despite the relatively abundant knowledge on many other aspects of the ecology of this species. 
Oviposition site selection has been studied in much greater detail in pond breeding species than that of arboreal species and these studies indicate that sites where eggs have been deposited can be influenced by the physical features of a breeding pond [20]. Laboratory and experimental pond observations have shown that both high and low temperatures have detrimental effects on embryos [21-23]. Therefore the timing of spawning may have effects on mortality in the field.

Here, I report about the correlative effect of rainfall on egg mortality of arboreal clutches of C. xerampelina. I also measured clutch size in relation to nest height and date of spawning of this species and discuss a few possible factors causing these variations.

\section{Materials and Methods}

\section{Study site}

This study was carried out from April $1^{\text {st }}$ to June $5^{\text {th }} 2011$ and from April $3^{\text {rd }}$ to June $10^{\text {th }} 2012$ at two ponds in the Vwaza marsh $\left(11^{\circ} 11^{\prime} 15.0 \mathrm{~S}, 33^{\circ} 27^{\prime} 34.3 \mathrm{E}\right)$ and the Vinthukutu forest reserve $\left(10^{\circ} 08^{\prime} 46.3 \mathrm{~S}, 34^{\circ} 11^{\prime} 07.1 \mathrm{E}\right)$ in Malawi. The Vinthukuzu forest reserve is located close to a lake shore in the Karona district. The reserve consists of dry miombo woodland in transition with partially green understory. The total extent of the reserve is $22 \mathrm{~km}^{2}$. A pond sized $20 \mathrm{x} 15 \mathrm{~m}$ and $1-50 \mathrm{~cm}$ of water depth was chosen as the study target within the forest. The ponds in this forest are characteristically small and shallow and the frogs lay eggs mostly on the emergent vegetation. The Vwasa marsh is seasonal flooded grassland drained by the alluvial plain of the Lewewe River. The Vwasa marsh is consequently deeper than the ponds at Vinthukuzu and the eggs are laid mainly on fringe vegetation and trees near the waterline. The target study area in Vwasa was located in a floodplain near Lake Kazuni. Within the study period, the size of the pond was $25 \times 20 \mathrm{~m}$ and the water depth varied from 10 to $100 \mathrm{~cm}$.

\section{Field monitoring of egg mortality}

To identify and quantify the possible factors determining egg mortality, a total of 73 nests were monitored at the Vwasa Marsh and the Vinthukuzu forest. C. xerampelina activity is high throughout this period [15]. The clutches were identified and located the morning after oviposition when the initial number of eggs was recorded. The clutches were subsequently checked twice a day until all the eggs had hatched or died. On the morning of the second day, a series of small containers (10 l) were hung with a small amount of pond water underneath each clutch for monitoring until the emergence of hatchlings [2,24]. When hatchlings began to drop the dead embryos and hatchlings were counted to determine clutch size and mortality.

During each visit, the number of live or dead hatchlings was recorded. Because hatchings fell into small containers below the clutch, missing animals were assumed to be removed by predators. Direct observations of egg predation were also made opportunistically. Submerged clutches, where hatchlings could not be contained by the small container as well as the number of drowned eggs characterized by developmental retardation, was recorded. Halted or impaired development in embryos was indicated by malformation, discolouration or fungal infection.

\section{Statistical analysis}

All analyses were conducted in $\mathrm{R}$ version 3.2.3. A linear regression analysis was used to test for a significant relation between egg mortality and the number of days after spawning first spawning. For example the number of eggs that died later on in the season. This analysis was also done for each year separate and then years combined.

A GLM Poisson regression analysis was used to examine the association between the height of the nests and the number of eggs. The analysis was performed for the data from each year separately, and then again for both years combined.

Differences in egg mortality between instances of rain and instances where there was no rain were examined to determine mortality rate. An examination of the distribution of the mortality figures suggested that they had a skewed distribution and were not normally distributed. As a result, the Mann-Whitney test was used to compare between the two sets of figures. This analysis was performed once separately per area and year. The number of eggs collected varied from day to day. As a result, the percentage of eggs that died on each given day was calculated.

\section{Results}

A total of 73 nests were found in the study ponds from the $1^{\text {st }}$ April to the $5^{\text {th }}$ June, 2011 and from the $3^{\text {rd }}$ April to the $10^{\text {th }}$ June, 2012. A total of 26,500 eggs were laid in the nests in 2011 and 29,748 eggs were laid in 2012 (56,248 overall). All eggs were attached to tree branches and leaves along the shores of the study areas. The number of eggs per nest ranged from 490 to 1113 ( $\overline{\mathrm{X}} \pm \mathrm{SD}=757.143 \pm$ 215.143; $\mathrm{n}=35)$ in 2011 and from 512 to $1023(\overline{\mathrm{X}} \pm \mathrm{SD}=784.38 \pm 173.717 ; \mathrm{n}=39)$ in 2012 . The average mortality of eggs was $29 \%$ in $2011(\overline{\mathrm{X}} \pm \mathrm{SD}=222.30 \pm 163.84)$ and $26 \%(\overline{\mathrm{X}} \pm \mathrm{SD}=197.37 .27 \pm 154.05)$ in 2012 from both ponds. In each nest examined, some eggs disappeared after the start of the third day. These eggs may have hatched or been eaten but their fate is unknown. Egg mortality after spawning differed between nests and varied from approximately 20 eggs lost during the first 3 days to 436 after 45 days (Figure 1). The mean mortality for nests selected was $197.94(S D=145.40 ; n=18)$ in 2011 and $195.94(S D=133.66 ; n=18)$ in 2012 . Overall mean for mortality in both years was $196.94(\mathrm{SD}=137.65 ; \mathrm{n}=36)$. Linear regression revealed a significant relationship between mortality and days after first spawning in $2011(\mathrm{P}=<0.01), 2012(\mathrm{P}=<0.01)$ and both years combined $(\mathrm{P}=<0.01)$. 


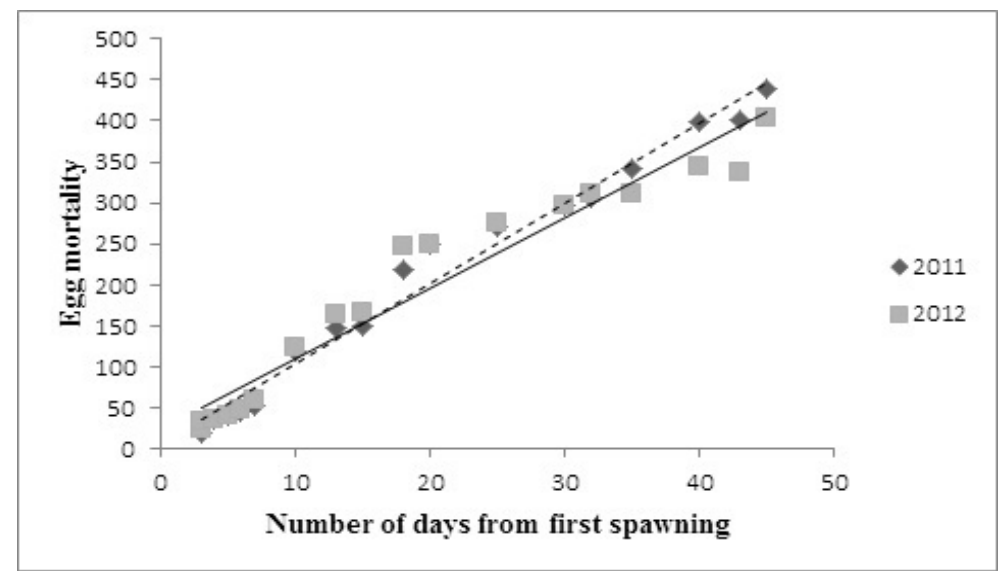

Figure 1: Relationship between average egg mortality and days after nest construction during the 2011 and 2012 breeding seasons. Dotted line shows the trend line for $2011\left(\mathrm{y}=9.831+4.6005 ; \mathrm{R}^{2}=0.981, \mathrm{P}<0.01\right)$, solid line shows the trend line for $2012\left(y=1968.9075 x+20.763 ; \mathrm{R}^{2}=0.9529, P<0.01\right)$

The height of the eggs over the water surface ranged from 0.50 to $5.6 \mathrm{~m}(\overline{\mathrm{X}} \pm \mathrm{SD}=2.89 \pm 1.69 ; \mathrm{n}=73)$ in both years. By year, the height of the eggs over the water surface ranged from $0.50 \mathrm{~m}$ to $5.6 \mathrm{~m}$ in 2011 ( $\overline{\mathrm{X}} \pm \mathrm{SD}=752.51 \pm 215.14 ; \mathrm{n}=35$ ) and from $0.50 \mathrm{~m}$ to $5.6 \mathrm{~m}$ in $2012(\overline{\mathrm{X}} \pm \mathrm{SD}=784.38 \pm 173.71 ; \mathrm{n}=39)$. The height of nests was associated with a significant decline clutch size (Figure 2$)$. This was applied for each year considered separately and also for the data from both years pooled together. There was a significant decline in clutch size in in 2011 (GLM, Z = - 42.05, P < 0.01) 2012 (GLM, Z = - 29.14, P < 0.01) and both years combined (GLM, Z $=-51.15, \mathrm{P}<0.01)$.

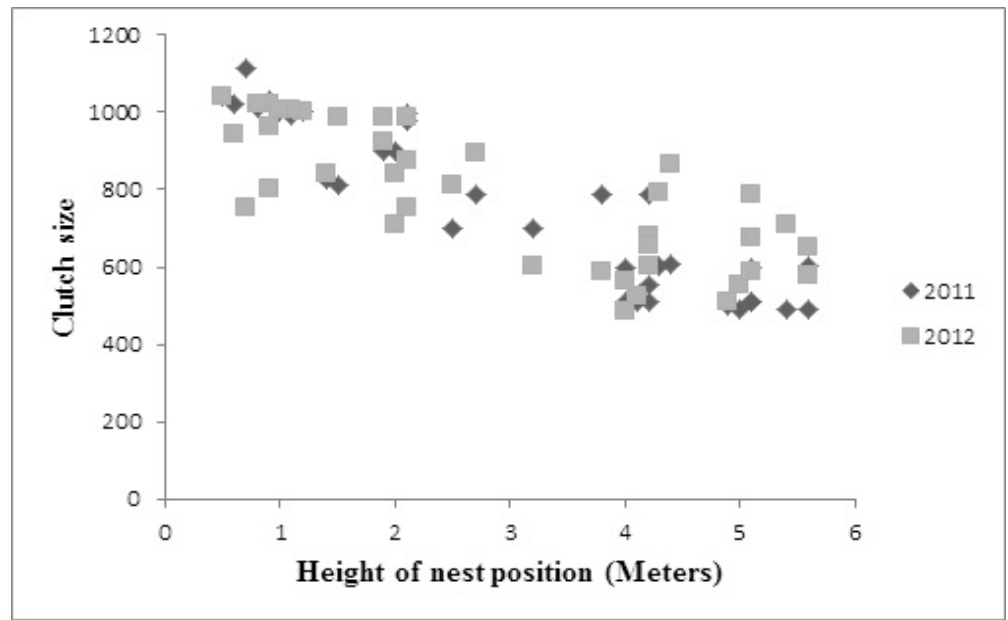

Figure 2: An increase in nest height position was associate with a significant decline in clutch size in $2011(\mathrm{P}<0.01)$ and $2012(\mathrm{P}<0.01)$

A lack of rainfall after the first 24 hours after oviposition increased egg mortality by $23 \%$ in 2011 and $18 \%$ in 2012 in Vinthukuzu and by $20 \%$ at Vwasa marsh in 2011 and $24 \%$ in 2012. The lack of rainfall significantly negatively affected egg mortality in 2011 and 2012 both at Vinthukuzu and Vwasa marsh (Figure 3). Mann Whitney U test indicated a highly significant Increase in egg mortality in eggs that had not been rained on in the first 24 hours in Vinthukutu and Vwasa marsh in 2011 and Vinthukutu and Vwasa marsh in 2012.

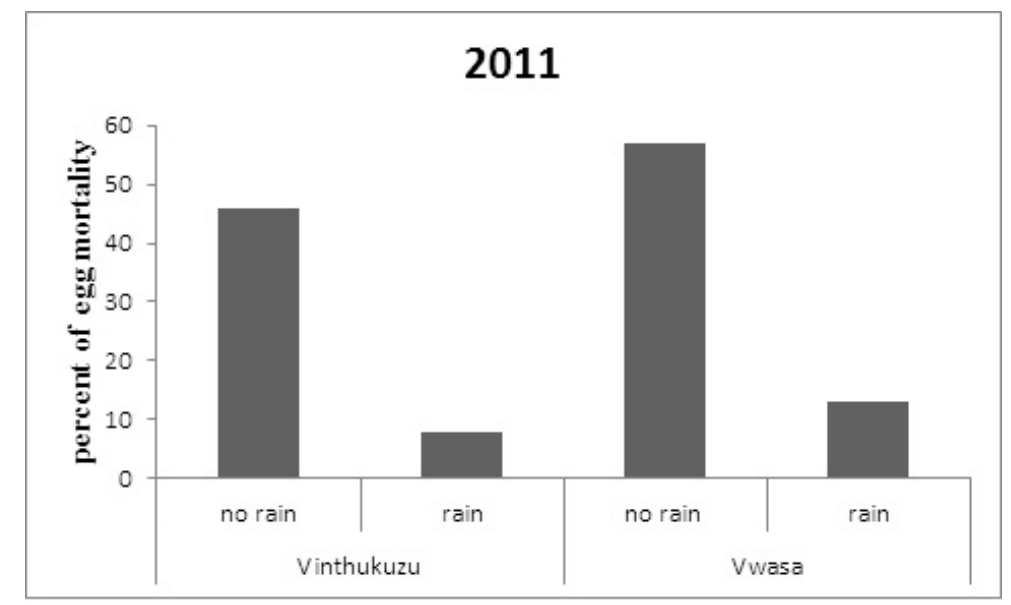




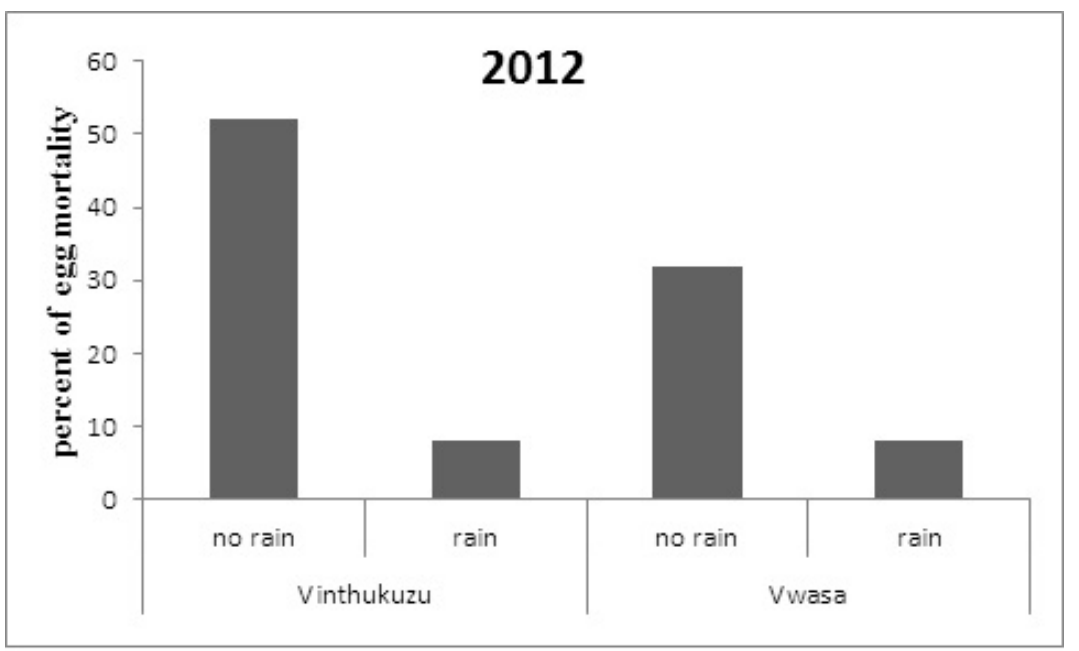

Figure 3: Timing of rainfall after oviposition effect on C. xerampelina egg mortality at two ponds. The percentage of total egg mortality increased in clutches not rained on at both ponds in 2011 at Vinthukuzu $(\mathrm{P}<0.01)$ and Vwasa Marsh $(\mathrm{P}<0.01)$ and in 2012 at Vinthukuzu $(\mathrm{P}<0.01)$ and Vwasa Marsh $(\mathrm{P}<0.01)$

\section{Discussion}

The effect that rainfall can have over a species biotic potential in arid ecosystems is well known $[25,26]$; however, the effect of short term fluctuations on anuran egg survival is less known. This is particularly important for frogs from African savannahs, as rainfall patterns are projected to change throughout the twenty-first century [6].

This study demonstrates the short-term effects of rainfall patterns over tree frog egg survival. C. xerampelina lays its eggs on plants above the water surface and they are consequently highly susceptible to relatively minor variations in environmental conditions. In addition, multiple environmental stressors are more lethal in combination than when considered separately [2]. These results show an increase in mortality following a dry period. In fact, the weather on the days following rainstorms is critical and long rainstorms stimulate spawning.

Large-scale climate fluctuations can have an effect on the ecology of many types of organisms including plants [27,28]. In fact, broad-scale climate patterns have been shown to better predict population dynamics than fine-scale weather measurements [13].

Information on egg mortality in foam nesting frogs is very limited. Mortality rates of 0.183 in R. arboreus [29] lower than that of other foam nesting frogs such as the Malaysian species Polypedates leucomystax (0.340) [30]. Mortality rates of foam nesting frogs are considered moderate compared to other anuran species. For example, the mortality rates reported for several pond breeding species vary from 0.024-0.426 [31-34]. The values reported range between 0.5-0.6 for a tropical hylid species [35]. Failure to fertilize [33,36], desiccation [2] fungal infection [37], low temperatures [38], predation [2] and radiation [39] are all known to increase egg mortality. Fly infestation as been shown to be the main cause of egg mortality in foam nesting frogs [30]. In this study, mortality from desiccation was frequently observed and the height of the nest over the water surface was shown to affect clutch size.

Large rainstorms are projected to become sporadic in this region with climate change [40,41]. Large rainstorms appear to stimulate more frogs to breed, suggesting that they have served as a reliable cue triggering reproduction. Habitat disturbance may interact with the projected less predictable rainfall patterns, potentially affecting egg mortality survival across multiple life stages.

\section{Acknowledgments}

I would like to thank Kayleigh Williams for her valuable advice. I would also like to thank Leila James and Daniel Shepard for their assistance during fieldwork. This research received financial support from Biosearch. Finally I wish to thank the Department of Parks and Wildlife for their support.

\section{References}

1. Duellman WE, Trueb L (1994) Biology of Amphibians, The Johns Hopkins University Press, Baltimore, Maryland, USA.

2. Touchon JC, Warkentin KM (2009) Negative synergism of rainfall patterns and predators affects frog egg survival. J Anim Ecol 78: 715-23.

3. Lipinski, VM, Dos Santos, TG, Schuch, AP (2016) An UV-sensitive anuran species as an indicator of environmental quality of the Southern Atlantic Rainforest. J Photochem Photobiol B 165: 174-81.

4. Wheeler CA, Bettaso JB, Ashton DT, Welsh HH Jr (2015) Effects of Water Temperature on Breeding Phenology, Growth, and Metamorphosis of Foothill Yellow Legged Frogs (Rana boylii): A Case Study of the Regulated Mainstem and Unregulated Tributaries of California's Trinity River. River Res Appl 31 : $1276-86$.

5. Altig R, Mcdiarmid R (2007) Morphological diversity and evolution of egg and clutch structure in amphibians. Herpetol Monogr 21: 1-32.

6. Solomon S, Qin D, Manning M, Chen Z, Marquis M, et al. (2007) Regional climate projections The Physical Science Basis In: Contribution of Working Group I to the Fourth Assessment Report of the Intergovernmental Panel on Climate Change 2007, Cambridge University Press, Cambridge, UK. 
7. Touchon JC, Worley JL (2015) Oviposition site choice under conflicting risks demonstrates that aquatic predators drive terrestrial egg-laying. Proc R Soc London B 282: 10.1098/rspb.2015.0376.

8. Donnelly MA, Crump ML (1998) Potential effects of climate change on two Neotropical amphibian assemblages. Clim Change 39: 541-61.

9. Chadwick R, Good P, Martin G, Rowell DP (2015) Large rainfall changes consistently projected over substantial areas of tropical land. Nat Clim Change 6: 177-81. 10. Morrison SA, Bolger DT (2002) Variation in a sparrow's reproductive success with rainfall: food and predator-mediated processes. Oecol 133: $315-24$.

11. Brown GP, Shine R (2007) Rain, prey and predators: climatically driven shifts in frog abundance modify reproductive allometry in a tropical snake. Oecologia 154: 361-8.

12. Benard MF (2015) Warmer winters reduce frog fecundity and shift breeding phenology, which consequently alters larval development and metamorphic timing. Global Change Biol 21: 1058-65.

13. Hallet TB, Coulson T, Pilkington JG, Clutton-Brock TH, Pemberton JM, et al. (2004) Why large-scale climate indices seem to predict ecological processes better than local weather. Nature 430: 71-5.

14. Almeida-Gomes M, Rocha CFD, Viera MV (2016) Local and Landscape Factors Driving the Structure of Tropical Anuran Communities: Do Ephemeral Ponds have a Nested Pattern? Biotropica 3: 365-72.

15. Poynton JC (2000) Foam-nest tree frogs in eastern Africa (Anura: Rhacophoridae Chiromantis): taxonomic complexities. Afr J Herpetol 49: 111-28.

16. Jennions MD, Bakwell PR, Passmore NI (1992) Breeding behaviour of the African frog, (Chiromantis xerampelina): multiple spawning and polyandry. Anim Behav 44: 1091-100.

17. Byrne PG, Whiting MJ (2008) Simultaneous polyandry increases fertilization success in an African foam-nesting tree frog. Anim Behav 76: 1157-64.

18. Byrne PG, Whiting MJ (2011) Effects of simultaneous polyandry on offspring fitness in an African tree frog. Behav Ecol 22: 385-91.

19. Liao WB, Mi ZP, Zhou CQ, Jin L, Lou SL, et al. (2011) Relative testis size and mating systems in anurans: large testis in multiple-male mating in foam-nesting frogs. Anim Biol 61: 225-38.

20. Kadadevarau CG, Kanamadi RD (2000) Courtship and nesting behaviour of the Malabar gliding frog, Rhacophorus malabricus (Jerdon 1870). Curr Sci 79: 377-80.

21. Kasuno T, Sumio SAH (2006) Ecological functions of the foam nests of the Japanese treefrog, Rhacophorus arboreus (Amphibia, Rhacophoridae). The Herpetol J 16: 163-9.

22. Smith GD, Hopkins GR, Mohammadi S, Skinner HM, Hansen T, et al. (2015) Effects of temperature on embryonic and early larval growth and development in the rough-skinned newt (Taricha granulosa). J Therm Biol 51: 89-95.

23. Norlin L, Byström P, Karlsson J, Johansson M, Liess A (2016) Climate change will alter amphibian-mediated nutrient pathways: evidence from Rana temporaria tadpoles in experimental ponds. Freshw Biol 61: 472-85.

24. Hayes MP (1983) A technique for partitioning hatching and mortality estimates in leaf-breeding frogs. Herpetol Rev 14: 115-6.

25. Hawkins BA, Field R, Cornel HV, Currie DJ, Guegan JF (2003) Energy, water, and broad-scale geographic patterns of species richness. Ecology 84: $3105-17$.

26. Deguines N, Brashares JS, Prugh LR (2016) Precipitation alters interactions in a grassland ecological community. J Anim Ecol 86: $262-72$.

27. Lawson CR, Vindenes Y, Bailey L, Pol M (2015) Environmental variation and population responses to global change. Ecol lett $18: 724-36$.

28. Stenneth NC, Mysterud A, Ottersen G, Hurell JW, Chan KS, et al. (2002) Ecological effects of climate fluctuations. Science 297: $1292-6$.

29. Toda M (1991) Survival rate of the Japanese tree frog Rhacophorus arboreus in Kanazawa Castle. Jap J Herpetol 14: 96.

30. Yorke CD (1983) Survival of embryos and larvae of the frog Polypedates leucomystax in Malaysia. J Herpetol 17: $235-41$.

31. Herreid CF, Kinney S (1966) Survival of Alaskan woodfrog (Rana sylvatica) larvae. Ecology 4: 1039-41.

32. Calef GW (1973) Natural mortality of tadpoles in a population of Rana aurora. Ecology 54: 741-58.

33. Beattie R, Tyler-Jones R (1992) The effects of low pH and aluminum on breeding success in the frog Rana temporaria. J Herpetol 26: 353-60.

34. Richter SC, Young JE, Johnson GN, Seigal RA (2003) Stochastic variation in reproductive success of a rare frog, Rana sevosa: Implications for conservation and for monitoring amphibian populations. Biol Cons 111: 171-7.

35. Warkentin KM (2000) Wasp predation and wasp-induced eggs hatching of red-eyed treefrog eggs. Anim Behav 60: 503-10.

36. Buzzato BA, Thyer EM, Roberts JD, Simmons LW (2016) Sperm competition and the evolution of precopulatory weapons: Testis size and amplexus position, but not arm strength, affect fertilization success in a chorusing frog. Evolution 71: 329-41.

37. Summers K (1999) The effects of cannibalism on Amazonian poison frog egg and tadpole deposition and survivorship in Heliconia axil pools. Oecol 119: 55764.

38. Waldman B (1982) Adaptive significance of communal oviposition in wood frogs (Rana sylvatica). Behav Ecol Sociobiol 10: 169-74.

39. Kiesecker JM, Blaustein AR (1995) Synergism between UV-B radiation and a pathogen magnifies amphibian embryo mortality in nature. Proc Natl Acad Sci U.S.A. 92: 11049-52.

40. Hulme M, Viner D (1998) A climate change scenario for the tropics. Clim Change 39: 145-76.

41. Trenberth KE, Dai A, van Der Schrer G, Jones PD, Barichivich J, et al. (2014) Global warming and changes in drought. Nat Clim Change 4: 17-22. 


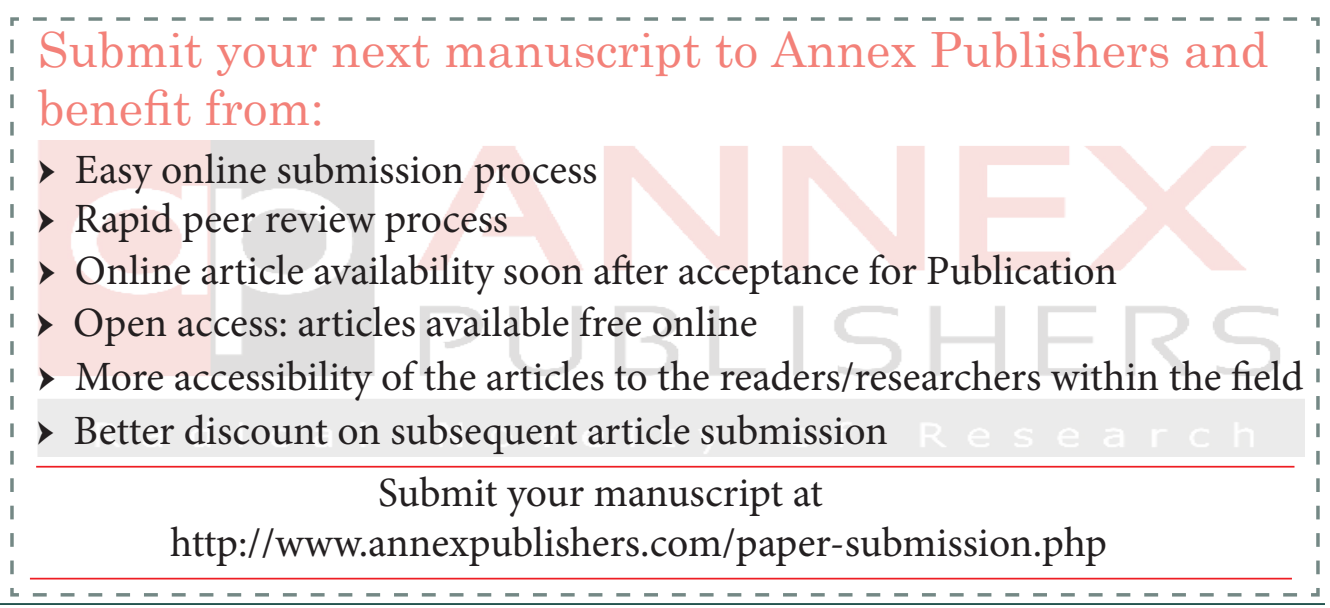

